\title{
The Temperature Dependence of Micro-Leakage between Restorative and Pulp Capping Materials by Cu Diffusion
}

\author{
H. Kamalak ${ }^{1}$, A. Mumcu ${ }^{2}$ and S. Altin ${ }^{3, *}$ \\ ${ }^{1}$ Inonu University, Faculty of Dentistry, Department of Restorative Dentistry, 44280, Malatya, Turkey; ${ }^{2}$ Inonu Univer- \\ sity, Scienctific and Technological Research Center, 44280, Malatya, Turkey; ${ }^{3}$ Inonu University, Science and Art Fac- \\ ulty, Physics Department, 44280 Malatya, Turkey
}

\begin{abstract}
We used the $\mathrm{Cu}$ ions for the leakage analysis between pulp capping and restorative materials. Theoretically, $\mathrm{Cu}$ has more advantages than $\mathrm{Ag}$ ions due to their smaller radii $\left(\mathrm{r}_{\mathrm{Cu}}{ }^{2+}=73 \mathrm{pm}\right.$ and $\left.\mathrm{r}_{\mathrm{Ag}}{ }^{2+}=94 \mathrm{pm}\right)$, lower mass density $\left(\mathrm{d}_{\mathrm{Cu}}=8.96\right.$ $\mathrm{g} / \mathrm{cm}^{3}$ and $\mathrm{d}_{\mathrm{Ag}}=10.49 \mathrm{~g} / \mathrm{cm}^{3}$ ) and higher radio opacity which can be more useful by X-ray or EDX detectors, cheaper price and more abundance in planet when compared with $\mathrm{Ag}$ element which is generally used in the leakage studies. The micro leakage between dental restorations and pulp capping materials has been determined by using Micro Computed Tomography, Scanning Electron Microscopy and EDX analysis. It is found that the leakage has temperature dependent mechanism which increases with the increasing temperature. As a result, using $\mathrm{Cu}$ solution for leakage studies in dentine is an effective and easy method which can be used in dental science.
\end{abstract}

Keywords: $\mathrm{Cu}$ diffusion, microleakage in dentin, $\mathrm{x}$-ray micro tomography.

\section{INTRODUCTION}

The leakage that is known as the diffusion of molecules, bacteria, fluids and ions from the cavity wall and the restorative material is one of the most important reasons for the failure and re-occurrence of restorations [1]. The microleakage occurs with the findings of secondary caries and pulp inflammation after a period following restorative materials implantation when postoperative sensitivity, fillings and tooth edge discoloration and leakage depth is profound [2, 3]. The leakage mechanism is important for understanding the pain after dental treatment and developing of the new materials [4-9].

Navarra et al. investigated the leakage ratio of different adhesive materials and they found that the leakage is strongly depend on the materials used during the dental treatment [13]. The other important factor for the leakage is the polymerization ratio of the materials and fast polymerization can cause a strong shrinkage and so the leakage may increase [10-15].

In recent years, the scientists use the micro-CT technique for the determination of the leakage in dentine. The technique is based on the radioopacity of the leaked materials and the most popular process is the using $\mathrm{Ag}$ ions for diffusion in dentine which can be detected by micro-CT. Radioopacity was defined as "the quality or property of obstructing the passage of radiant energy such as x-ray". The radioopacity of matters such as elements and tissues depends on the atomic number i.e. higher atomic number results higher radioopacity [16-21].

*Address correspondence to this author at the Inonu University, Science and Art Faculty, Physics Department, 44280, Malatya, Turkey;

Tel: +90 422377 3739; Fax: +90 42234103 19;

E-mail: serdar.altin@inonu.edu.tr
We used the $\mathrm{Cu}$ ions for leakage analysis between the pulp capping and restorative materials. $\mathrm{Cu}$ ions have more advantages than $\mathrm{Ag}$ ions due to their smaller radii $\left(\mathrm{r}_{\mathrm{Cu}^{2+}}{ }^{2+}=73\right.$ pm and $\left.\mathrm{r}_{\mathrm{Ag}}{ }^{2+}=94 \mathrm{pm}\right)$, lower density $\left(\mathrm{d}_{\mathrm{Cu}}=8.96 \mathrm{~g} / \mathrm{cm}^{3}\right.$ and $\mathrm{d}_{\mathrm{Ag}}=10.49 \mathrm{~g} / \mathrm{cm}^{3}$ ), cheaper price and more abundance in planet when compared with $\mathrm{Ag}$ element $[22,23]$. So, we expected that the diffusion of $\mathrm{Cu}$ ions should be faster than $\mathrm{Ag}$ due to their smaller radii than $\mathrm{Ag}$ ions.

The aim of this study is to reveal the mechanism and the reasons of the leakage between restorative materials and $\mathrm{Ca}(\mathrm{OH})_{2}$ of pulp capping materials by using $\mathrm{Cu}$ solution. We fabricated a dentine like sample and the $\mathrm{Cu}$ solutions with different pressure and temperatures for simulation of various states in mouth. After this process, the cross section of the samples was investigated by Scanning electron microscopy (SEM), energy dispersive x-ray spectroscopy (EDX), Micro$\mathrm{CT}$ analysis. The diffusion mechanisms of the intersection regions were investigated by EDX elemental dot analysis.

\section{MATERIAL-METHODS}

Dycal, $\mathrm{Ca}(\mathrm{OH})_{2}$ pulp capping material was placed into the cylindrical molds of $5 \mathrm{~mm} \times 1.5 \mathrm{~mm}$. After dycal was removed from within the cylindrical mold, Clearfil SE Bond (Kuraray, Japan) bonding agent was applied as a layer on the capping material. Clearfil SE Bond (Bottle) consists of two components, primer and light-cured bonding agent. After applying primer and dry with mild air for 5 seconds, bonding agent was applied for 10 seconds. For making uniform bond film, a gentle air flow was applied. Then, samples were polymerized with LED (Light Emitting Diode) which has a wavelength of $400 \mathrm{~nm}$ for min 10 seconds. Prepared $\mathrm{Ca}(\mathrm{OH})_{2}$ sample was placed into the $9 \times 2 \mathrm{~mm}$ cylindrical molds. Then, Voco Arabesk Composite Resin (Cuxhaven, Germany) was placed on the $\mathrm{Ca}(\mathrm{OH})_{2}$. Transparent band was 
placed on the sample and the samples were polymerized for 40 seconds as schematically shown in the Fig. (1).

The prepared samples that removed from the molds were placed into the bottles containing $0.1 \mathrm{~N} \mathrm{Cu}\left(\mathrm{NO}_{3}\right)_{2}$ then a 8 $\mathrm{kg} / \mathrm{cm}^{2}$ load was applied to the sample. Each of the samples is incubated in water bath for the temperature range of $30{ }^{0} \mathrm{C}$ $55{ }^{\circ} \mathrm{C}$, with an increase of $5{ }^{\circ} \mathrm{C}$ by using Julabo 5 water bath for 12 hours. After thermal processing, microleakage investigations between the pulp capping material and the restorative material were analyzed by Micro CT (Micro Computed Tomography Model 1172) device. Then, in order to examine the micro leakage in cross section of the sample and the leakinduced diffusion mechanism, it was cut into two slices with IsoMet 1000 Precision Saw device. The surface morphology and elemental distribution analysis in the cross section area were analyzed by SEM, Leo Evo $40 \mathrm{VP}$ and Bruker EDX unit combined by SEM system.

\section{RESULTS AND DISCUSSION}

We investigated the diffusion mechanism in the interface region of the fabricated samples by cutting the sample in the middle after $\mathrm{Cu}$ diffusion for different temperature for $12 \mathrm{~h}$. Fig. (2) shows the $\mathrm{Cu}$ dot mapping analysis for the interface region of sample processed for different thermal treatments. As seen in the Fig. (2), some region dot intensities are higher than that of the other region which means the higher amount of $\mathrm{Cu}$ in the cross-section.

$\mathrm{Cu}$ concentration is higher in the region close to the surface of the material. It also appears that some regions during the interface section have higher dot intensity which is an evidence of the leakage between the pulp capping material and the restorative materials. Actually, we only investigated one cross-section of the sample (2D analysis), if we cut the sample into different slices, it will be seen that there are a number of $\mathrm{Cu}$ rich regions in the sample. So, the micro structural investigations in this study give us a road map for leakage mechanism between the restorative materials and pulp capping materials in dental science.

The $\mathrm{Cu}$ distribution of the sample processed at $30^{\circ} \mathrm{C}$, have huge $\mathrm{Cu}$ content as seen in Fig. (3) which is not customary during the study. So, when we investigate the reason of high $\mathrm{Cu}$ content in the cross section of the sample, it was found that there is a big crack in the interface of the sample. This result has important conclusion for the leakage studies in the dental science. The improper application of dental treatments gives unusually big leakage and so, the patient suffers just after dental treatments.

In order to examine quantitatively the amount of diffused $\mathrm{Cu}$ ions, $\mathrm{Cu}$ content was determined by EDX dot analysis (Fig. 2) from surface to substructure of the interface region and we investigated the $\mathrm{Cu}$ leakage in the system. According to EDX dot analysis, it is clear that there was a definite leakage in the interface region of pulp capping and restorative materials. The cracks and holes which were formed during the dental treatment have energetically metastable regions and they easily cause an accumulation of $\mathrm{Cu}$ ions in these regions hence the $\mathrm{Cu}$ ions in these regions trigger the growing of holes and cracks. Furthermore, the thermal fluctuations due to consuming of hot and cold foods can cause the growing of the hole and crack regions. In this condition, the leaked materials inside the tooth reach the nerve region of tooth which causes pain to the patient. Furthermore, it can also cause the percolation, secondary decay, post-operative sensitivity and disappearing of aesthetics after staining.

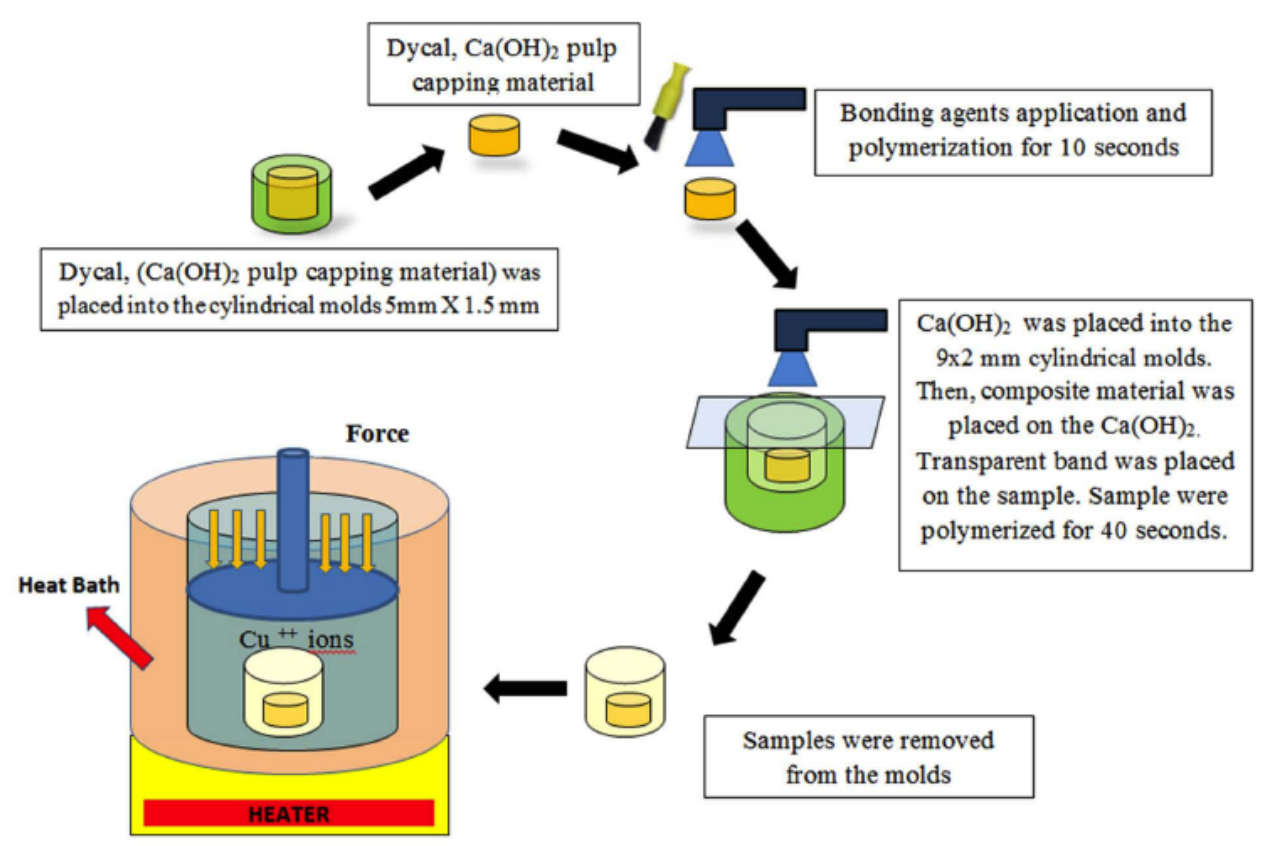

Samples were subjected to thermal and loading cycles

Fig. (1). The illustration of the sample fabrication and diffusion process. 


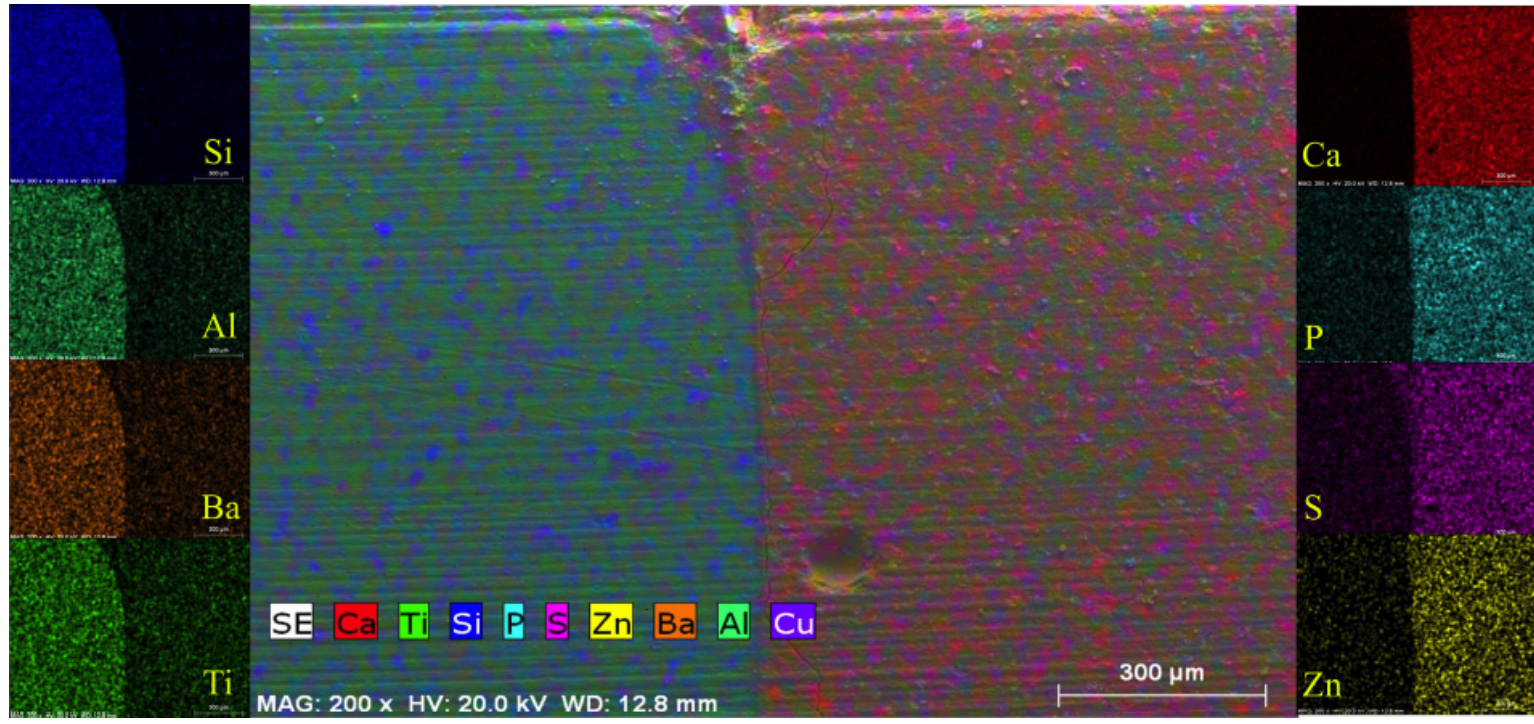

Fig. (2). EDX dot mapping in the cross-section region of the sample.
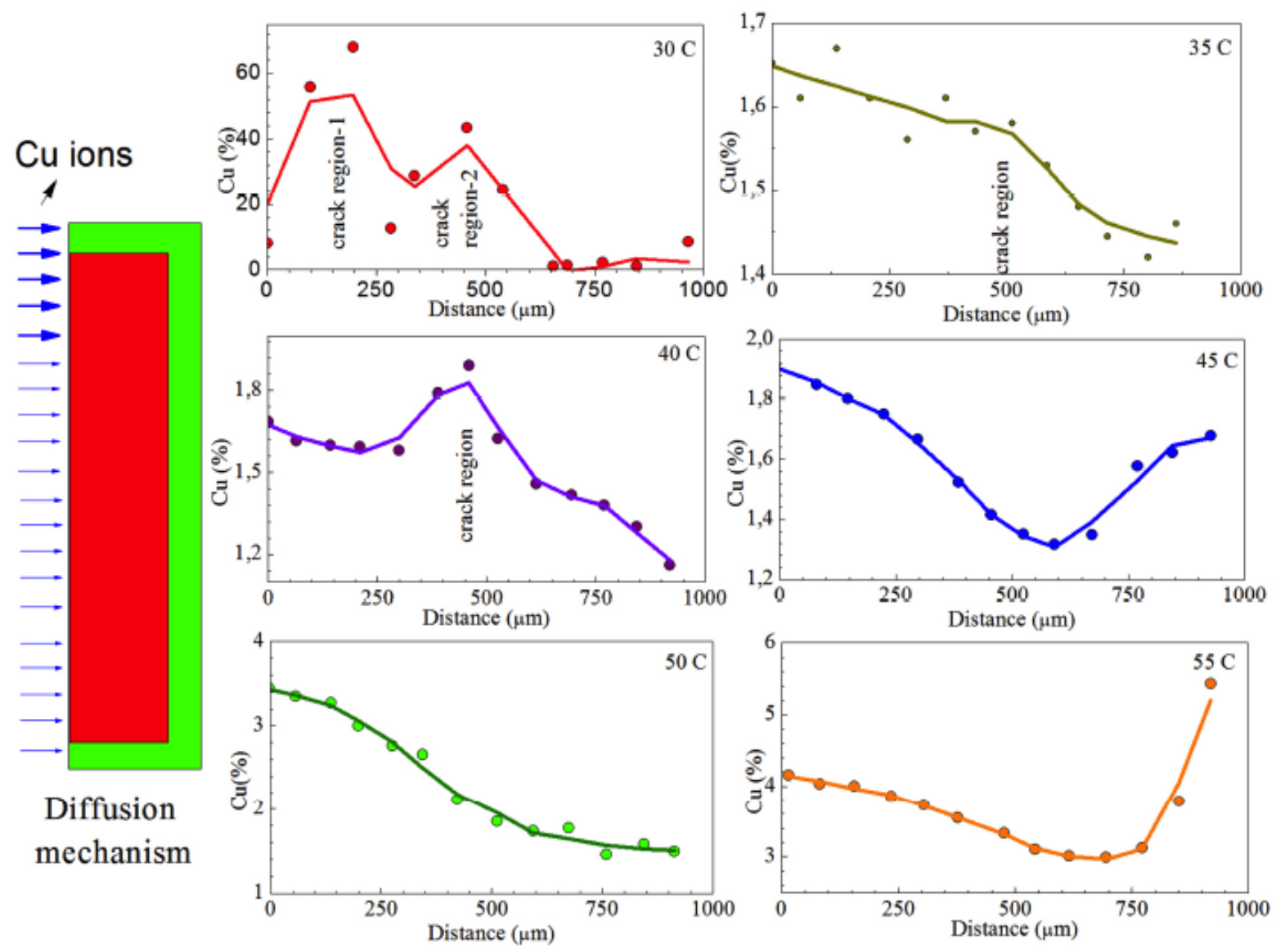

Fig. (3). The temperature dependence $\mathrm{Cu}$ leakage into the sample obtained from EDX dot analysis in the connection region. The high $\mathrm{Cu}$ diffusion in (a) due to cracks and the left schema illustrate the diffusion of $\mathrm{Cu}$ ions in the designed sample.

The leakage mechanism between the restorative and pulp capping materials has great importance for the development of the ways to treat and determine the exact reason of pain after dental surgery and relief it. Fig. (3) shows the $\mathrm{Cu}$ concentration change with distance from surface to following regions of the samples depending on the thermal treatments. Basically, the expected change of $\mathrm{Cu}$ concentration with distance after diffusion should be in the form of exponential decrease curve from the surface and there should be an accumulation in the subsequent region of the interface regions. Although the obtained curve from EDX dot mapping analysis shows almost expected structure as mentioned above, some dots in the interface region have higher concentration than that of the other regions as seen in Fig. (3). This case is 
an evidence of the discussion given in previous section. So, the EDX dot mapping process for the determination of the leakage mechanism in the tooth study is a reliable method for this kind of studies. The obtained results demonstrate that $\mathrm{Cu}$ ions can easily diffuse to interface region and cause the deformation of the materials. The ionic radii of $\mathrm{Cu}$ ions are greater than the other elements such as $\mathrm{C}, \mathrm{B}, \mathrm{H}$ and $\mathrm{N}$ and it is important for human life. So, we concluded that the atoms or ions which are smaller radii can diffuse and easily reach the nerve inside the tooth.

According to Fig. (3), the concentration of $\mathrm{Cu}$ ions was increased by increasing the thermal treatment temperatures. The increase of the $\mathrm{Cu}$ content with temperature is expected. Because an increase in the temperature will increase the kinetic energy and the oscillation frequency of the atoms, so the mobility of the diffused atoms will increase then it can cause the increase of diffusion rate and concentrations.

$\mathrm{Cu}$ ions in the solution diffuse from regions of higher concentration to regions of lower one with heat treatment and time. Therefore, the percentage concentration of $\mathrm{Cu}$ ions in the material changed with increasing the heat treatment conditions such as temperature and time. If the concentration at some point changes with time, Fick's second diffusion law can be used [22]. We assume that $\mathrm{Cu}=100 \%$ for $\mathrm{x}>+\mathrm{L}$ and $\mathrm{x}<-\mathrm{L}, \mathrm{Cu}=0$, for $-L \leq x \leq+L$ at $\mathrm{t}=0$. When diffusion starts $(\mathrm{t}>0)$, the concentration of $\mathrm{Cu}$ in the designed material region changes with the time and temperature. A solution of the diffusion equation in this case can be obtained in the following manner: Imagine that the diffused region for $\mathrm{Cu}$ ions consists of $n$ slices. If $\alpha_{i}$ is the distance from the center of the $\mathrm{i}$ th slice to $\mathrm{x}=0$, When $\mathrm{n} \rightarrow \infty$ and $\Delta \alpha_{\mathrm{l}} \rightarrow 0$, The solution of this approach is the form of error function as given below;

$$
c(x, t)=\frac{c^{l}}{2}\left(1+\operatorname{erf}\left(\frac{x}{2 \sqrt{D \cdot t}}\right)\right)
$$

Diffusion coefficients for $\mathrm{Cu}$ ions were calculated by substituting of the obtained concentration values. The calculated diffusion coefficients are presented in Fig. (4) depending on heat treatment conditions. It is found that the diffusion coefficient increases with the increasing temperature and this is due to thermal fluctuations and vibrations of ions in the samples.

3D top-view micro-CT images of samples unprocessed and processed by $\mathrm{Cu}$ were given in Fig. (5a and $\mathbf{b}$ ), respectively. It is obvious that the unprocessed sample has two different regions in Fig. (5a) where the outer side is restorative material and the inner side is pulp capping material as mentioned SEM, EDX section. The Micro-CT images have white intense regions due to $\mathrm{Cu}$ treatment on the surface section of inner part of the sample designed as seen in Fig. (5b), the outer part has no clue about $\mathrm{Cu}$ aggregation. So we concluded that pulp capping material has an ability to accumulate of diffuse materials. This result will lead to new studies for the modification of pulp capping materials.

Different cross-sectional views of the unprocessed and $\mathrm{Cu}$ diffused samples obtained by Micro-CT analysis, are given in Fig. (6A-E). In the axial section of the unprocessed sample, it is found to be any radio-opacity between pulp capping material and restorative materials. On the other hand, there are porosities inside the sample and the radio opacity in the joining region of the pulp capping and restorative materials should be due to $\mathrm{Zn}$ ions of pulp capping material as seen in Fig. (6A). Similar observation was also obtained in the sagittal section of unprocessed sample as seen in Fig. (6B).

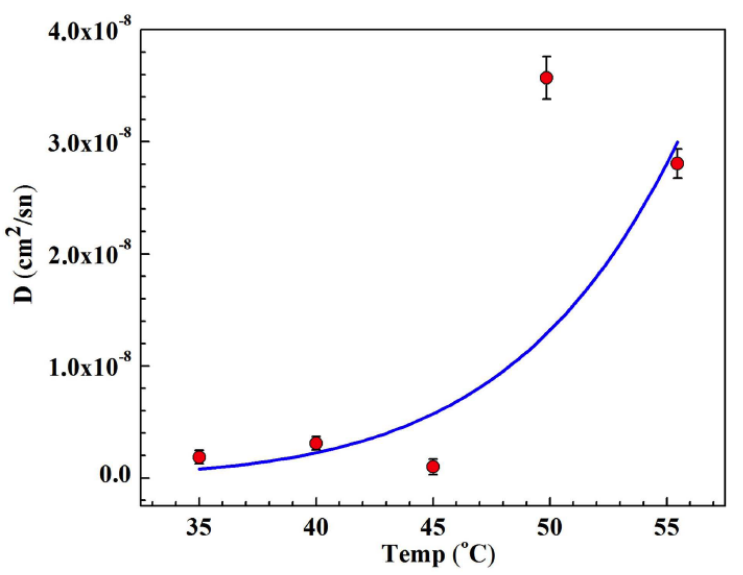

Fig. (4). Temperature dependence of diffusion coefficient of the interface region of the samples.

The dense accumulation of $\mathrm{Cu}$ was observed especially the surface of pulp capping materials as the cross-section of the $\mathrm{Cu}$ processed sample is seem in Fig. (6C). The yellow arrows in the Figs. (6D and $\mathbf{E}$ ) indicate the radio-opac regions in the processed sample which are a good example of the diffusion of $\mathrm{Cu}$ ions inside the sample. The red circle shows the holes (Porosity regions) formed during the sample fabrications and the white arrows show the holes (Porosity regions) which have high $\mathrm{Cu}$ concentration among them, Fig. $(\mathbf{6 E})$. So, we predicted that the porosity regions have high potential for $\mathrm{Cu}$ accumulation inside it because of the holes and crack regions have higher free energy than the other region of the materials and the diffused elements can easily accumulate in these regions. Meanwhile, avarage pixel values of radio opacity of $\mathrm{Cu}$ diffused sample are shown in the Fig. (6F) and pixel values of depth of penetration of leaked $\mathrm{Cu}$ ions are shown in Fig. (6G).

The hole radii in the samples observed by MicroCT were measured for the unprocessed and $\mathrm{Cu}$ diffused samples and it was found that the radii of holes increased with $\mathrm{Cu}$ diffusion which indicates the settlement of $\mathrm{Cu}$ ions in these regions. This result is important for the leakage studies since the leakage time depends on the diffusion of elements.

In the leakage studies, it is well known that there is no remarkable effect by adhesion resin and the type of pulp capping and restorative materials can cause the leakage mechanism. As a result, it is obvious that the diffusion rate and so micro-CT images will change by the sample to sample and also preparation conditions, but our principal goal is to show that the leakage studies in dental research by $\mathrm{Cu}$ diffusion method are much reliable and cheaper method than the others such as Ag leakage studies. 

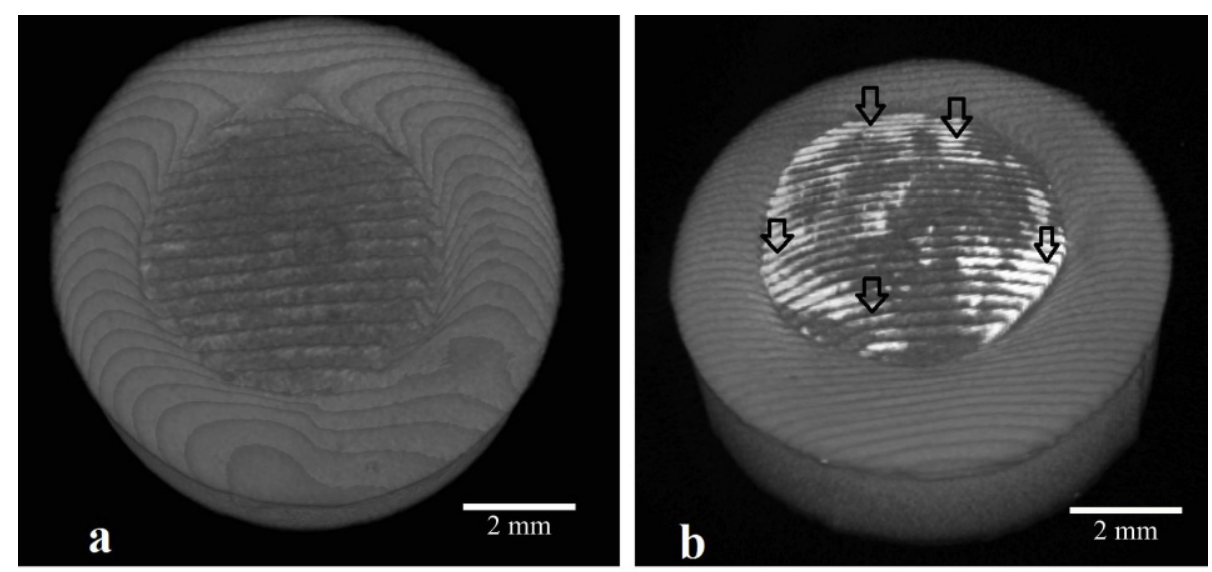

Fig. (5). (a) 3D Micro-CT images of the unprocessed sample which the outer side is restorative material and the inner side is pulp capping material and (b) 3D Micro-CT images of the sample which exposed to copper. (image has white intense regions shown by the black arrow due to $\mathrm{Cu}$ treatment on the surface).
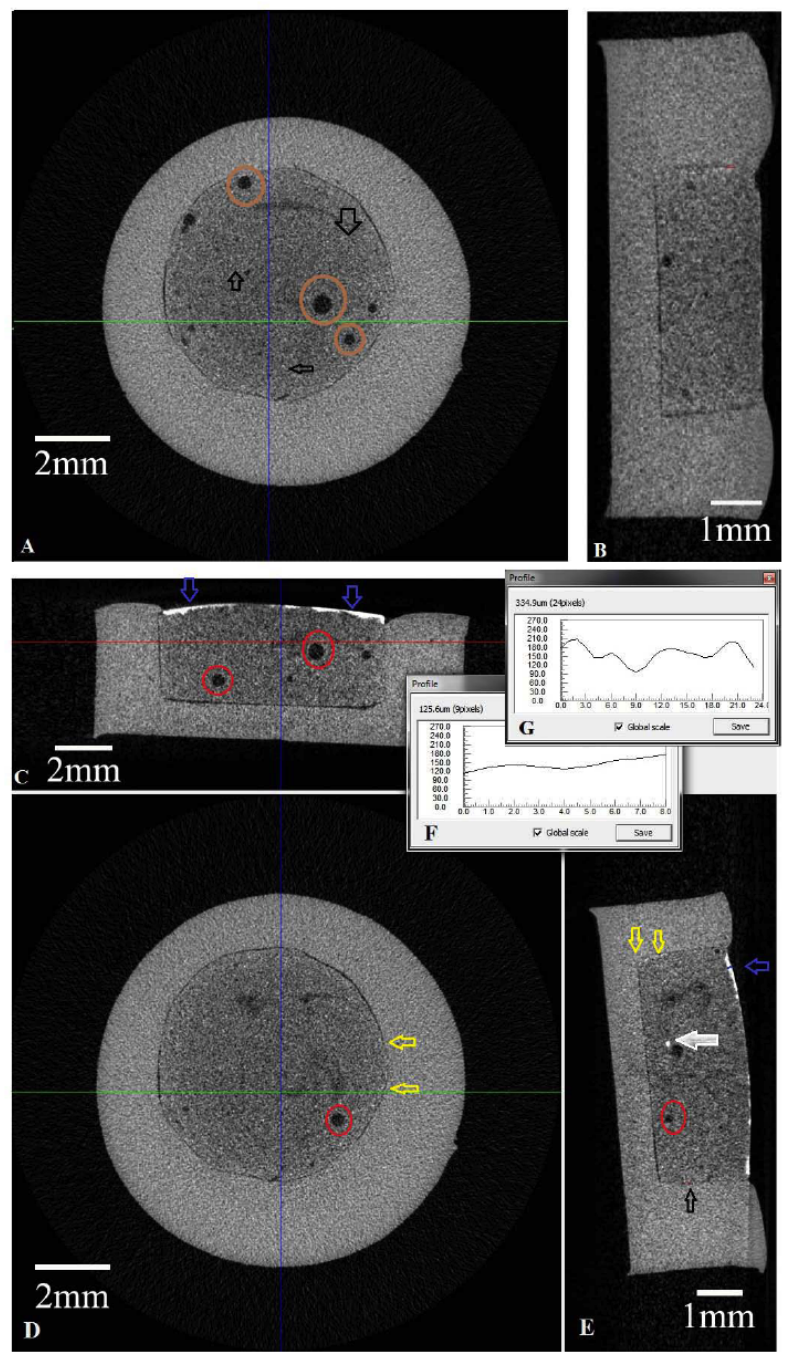

Fig. (6). (A) Axial cross-secitonal view of the unprocessed sample (B) Sagital cross-sectional view of unprocessed sample (C) Coronal sectional view of $\mathrm{Cu}$ diffused sample (D) Axial cross-secitonal view of the $\mathrm{Cu}$ diffused sample (E) Sagital cross-sectional view of $\mathrm{Cu}$ diffused sample (F) Avarage pixel values of radio opacity of $\mathrm{Cu}$ diffused sample (G) Pixel value of depth of penetration of leaked $\mathrm{Cu}$ ions.

\section{CONCLUSION}

In this study, we presented the microstructure and mechanism of the diffusion and leakage between restorative and pulp capping material by using $\mathrm{Cu}$ solution. It is concluded that $\mathrm{Cu}$ ions can be used for the leakage or diffusion studies in dental research since $\mathrm{Cu}$ ions have different advantages as mentioned before such as the price and abundance in the planet. The diffusion calculations showed that leakage is increased for hot environment and the regions which havecracks and holes occured during the dental treatment or after dental treatment. Furthermore using $\mathrm{Cu}$ solution for diffusion in dentine is an effective and easy method, it is necessary to carry out further studies by using $\mathrm{Cu}$ ions in the leakage studies.

\section{CONFLICT OF INTEREST}

The authors confirm that this article content has no conflict of interest.

\section{ACKNOWLEDGEMENTS}

This study was supported by the Inonu University research council under contract number 2013-74.

\section{ETHICAL APPROVAL}

This study does not need the ethical approval because we didn't use any living organism during the experiments.

\section{REFERENCES}

[1] Rechenberg DK, Deus G, Zehnder M. Potential systematic error in laboratory experiments on microbial leakage through filled root canals: review of published articles. Int Endodont J 2011; 44: 183-94. Mannocci F, Ferrari M, Watson T. Micro leakage of endodontically treated teeth restored with fiber posts and composite cores after cyclic loading: a confocal microscopic study. J Prosthetic Dent 2001; 85: 284-91.

[3] Waldman GL, Vaidyanathan TK, Vaidyanathan J. Micro leakage and resin to dentin interface morphology of pre-etching versus selfetching adhesive systems. Open Dent J 2008; 2: 120-5.

[4] Alani AH, Toh CG. Detection of microleakage around dental restorations: a review. J Oper Dent 1997; 22: 173-85. 
[5] Mousavinasab SV, Atai M, Alavi B. To compare the micro leakage among experimental adhesives containing nanoclay fillers after the storages of 24 Hours and 6 Months. Open Dent J 2011; 5: 52-7.

[6] Franco EB, Gonzaga LL, Mondelli RF, Silva E, Souza MH, Lauris JR. Effect of the cavity configuration factor on the marginal micro leakage of esthetic restorative materials. Am J Dent 2003; 16: 21114.

[7] Prati C, Nucci C, Montanari G. Shear bond strength and micro leakage of dentine bonding systems. J Prosthetic Dent 1991; 65: 401-7.

[8] Rossomando K, Wendt S. Thermocycling and dwell times in micro leakage evaluation for bonded restorations. Dent Mater 1995; 11: 47-51.

[9] Wijaya SK, Oka H, Saratani K, Sumikawa T, Kawazoe T. Development of implant movement checker for determining dental implant stability. J Med Engine Phys 2004; 26: 513-22.

[10] Chinelatti MA, Corona SAM, Borsatto MC. Analysis of surfaces and adhesive interfaces of enamel and dentine after different treatments. J Mater Sci 2007; 18: 1465-70.

[11] Dejou J, Sindres V, Camps J. Influence of criteria on the results of in vitro evaluation of microleakage. Dent Mater 1996; 12: 342-9.

[12] Wu M, Wesselink P. Endodontic leakage studies reconsidered. Part I. Methodology, application and relevance. Int Endodont J 1993; 26: 37-43.

[13] Navarra CO, Cadenaro M, Codan B, Mazzoni A, Sergo V, Dorigo E, Breschi L. Degree of conversion and interfacial nanoleakage expression of three one-step self-etch adhesives. Eur J Oral Sci 2009; 117: 463-9.
[14] Grossman ES, Matejka JM. In vitro marginal leakage in varnished and lined amalgam restorations. J Prosthet Dent 1993; 69: 469-74.

[15] Borkowskia K, Kotousova A, Kahler B. Effect of material properties of composite restoration on the strength of the restoration dentine interface due to polymerization shrinkage, thermal and occlusal loading. J Med Engine Phys 2007; 29: 671-6.

[16] Triadan H. When is microleakage a real clinical problem? J Oper Dent 1987; 12: 153-7.

[17] Cottenden AM, Dean GE, Brooks RJ. Predicting the leakage performance of small bodyworn disposable incontinence pads using laboratory tests. J Med Engine Phys 1997; 19: 556-71.

[18] Williams DF. The Williams Dictionary of Biomaterials: Liverpool University Publishing 1999.

[19] He J, Soderling E, Vallittu PK, Lassila LV. Preparation and evaluation of dental resin with antibacterial and radio-opaque functions. Int J Mol Sci 2013; 14: 5445-60.

[20] Dukic W, Delija B, Derossi D, Dadic I. Radiopacity of composite dental materials using a digital X-ray system. Dent Mater J 2012; 31: 47-53.

[21] Pekkan G, Pekkan K, Hatipoglu MG, Tuna SH. Comparative radiopacity of ceramics and metals with human and bovine dental tissues. J Prosthet Dent 2011; 106: 109-17.

[22] Shewmon GP. Diffusion in Solids, New York: McGraw Hill 1963.

[23] Tang WW, Zeng GM, Gong JL, Liang J, Xu P, Zhang C, Huang BB. Impact of humic/fulvic acid on the removal of heavy metals from aqueous solutions using nanomaterials: a review. Sci Total Environ 2014; 468: 1014-27.

(C) Kamalak et al.; Licensee Bentham Open.

This is an open access article licensed under the terms of the Creative Commons Attribution Non-Commercial License (http://creativecommons.org/licenses/by-nc/3.0/) which permits unrestricted, non-commercial use, distribution and reproduction in any medium, provided the work is properly cited. 